\title{
Neurogenic Shock
}

National Cancer Institute

\section{Source}

National Cancer Institute. Neurogenic Shock. NCI Thesaurus. Code C50671.

Shock resulting from neurogenic vasodilation, which can be produced by cerebral trauma or hemorrhage, spinal cord injury, deep general or spinal anesthesia, or toxic central nervous system depression. 